\title{
ENSINO DE LÍNgUAS PARA Fins EsPecíficos NO IFAL: ANÁLISE DE NECESSIDADES DOS USOS DAS LÍNGUAS ESPANHOLA E INGLESA ${ }^{1}$
}

\author{
LANGUAGE TEACHING FOR SPECIFIC PURPOSES AT IFAL: ANALYSIS OF \\ NEEDS FOR SPANISH AND ENGLISH LANGUAGE USES
}

DOI: 10.23926/RPD.2526-2149.2020.v5.n2.p743-763.id644

\section{Claudemir Cândido da Silva \\ Graduado em Hotelaria \\ Graduando em Letras-Inglês \\ (UFAL) \\ odidcancandido@gmail.com}

\section{Diana Gleise dos \\ Santos Ferraz}

Graduanda em Gestão de

Turismo (IFAL)

gleiseferraz@gmail.com

\section{Christiane Batinga}

Agra

Doutoranda em Linguística

(UFAL)

Mestra em Linguística

(UFAL)

Professora no Instituto

Federal de Alagoas (IFAL)

christianeagra@hotmail.com

\section{Flávia Karolina Lima- \\ Duarte}

Doutora em Linguística

(UFAL)

Professora no Instituto

Federal de Mato Grosso

(IFMT)

flaviakarolinalima@gmail.co

$\underline{\mathrm{m}}$
Resumo: Este trabalho teve como objetivo verificar as necessidades de usos das línguas espanhola e inglesa no curso Tecnológico em Hotelaria a partir das percepções de profissionais que atuam no ramo hoteleiro, turistas estrangeiros e estudantes. O referencial teórico está representado por estudos das áreas de ensino de línguas para fins específicos e análise de necessidades. A metodologia foi realizada em três etapas e utilizouse questionários semiestruturados como instrumento de coleta e geração de dados. Os resultados demonstram que os funcionários dos hotéis não se sentem preparados para interagir verbalmente com os turistas estrangeiros, fato corroborado por esses turistas que apontam para a necessidade de os profissionais adquirirem o vocabulário básico da área. Além disso, percebemos também que os estudantes desconhecem suas necessidades em relação à aprendizagem dessas línguas. Como conclusão, observa-se a necessidade de ofertar formação aos profissionais que atuam nos hotéis e de reformular as ementas das duas disciplinas no curso de hotelaria.

Palavras-chave: Análise das necessidades. Ensino de línguas para fins específicos. Hotelaria.

\begin{abstract}
This research aimed to verify the needs of uses of the Spanish and English languages in the Technological course in Hospitality, from the perceptions of professionals working in the hotel business, foreign tourists and students. The theoretical framework is represented by studies in the areas of language teaching for specific purposes and needs analysis. The methodology was carried out in three stages and semistructured questionnaires were used as an instrument for data collection and data generation. The results show that hotel employees do not feel prepared to verbally interact with foreign tourists, a fact corroborated by these tourists who point to the need for professionals to acquire the basic vocabulary of the area. In addition, we also realize that students are unaware of their needs in relation to learning these languages. As a conclusion, there is a need to offer training to professionals who already work in the hotel and to reformulate the menus of the two subjects in the hotel.
\end{abstract}

Keywords: Needs analysis. Language teaching for specific purposes. Hospitality.

\footnotetext{
1 Agradecemos à Coordenação de Aperfeiçoamento de Pessoal de Nível Superior (CAPES), à Fundação de Amparo à Pesquisa do Estado de Alagoas (FAPEAL) e à Pró-Reitoria de Pesquisa do Instituto Federal de Alagoas (PRPI/IFAL) por viabilizarem a execução financeira desta pesquisa.
} 


\section{INTRODUÇÃO}

Desde o segundo semestre de 2009 o Instituto Federal de Alagoas, campus Maceió, oferta o curso tecnológico em hotelaria na modalidade presencial. Este curso tem duração de cinco semestres e em todos são ofertadas as disciplinas de língua espanhola e língua inglesa, contudo, desde seu início até os dias atuais, não foi realizado nenhum estudo que verificasse quais as reais necessidades dos estudantes e futuros profissionais da área.

As ementas dessas disciplinas foram elaboradas pelos professores de línguas espanhola e inglesa que atuam no curso com base em suas práticas de sala de aula. Embora compreendamos que a experiência docente seja importante nesse processo de elaboração das ementas, consideramos que um estudo mais aprofundado poderá contribuir para que o Ensino de Línguas para Fins Específicos (ELFE) atenda as reais necessidades, no que se refere à comunicação em língua estrangeira, do futuro profissional da área de hotelaria.

Diante do exposto, temos como objetivo verificar as necessidades de usos das línguas espanhola e inglesa no curso Tecnológico em Hotelaria a partir das percepções de profissionais que atuam no ramo hoteleiro, turistas estrangeiros e estudantes. Para alcançar este objetivo, esta pesquisa buscou triangular os dados com base na teoria da análise de necessidades proposta por Hutchinson e Waters (1987), com adaptações necessárias ao nosso contexto.

Para tanto, este artigo se divide em três partes além desta introdução. Na primeira tecemos algumas considerações teóricas sobre o ensino de línguas para fins específicos e análise das necessidades. Na segunda, descrevemos os procedimentos metodológicos de coleta e geração dos dados. Na terceira, apresentamos três seções de análise de necessidades a partir das perspectivas dos (1) funcionários dos hotéis; (2) turistas e (3) estudantes do curso de hotelaria do IFAL. Por fim, tecemos algumas considerações sobre as implicações desta pesquisa para reformulação das ementas do curso tecnológico em hotelaria e de políticas públicas que invistam principalmente em ações voltadas para o atendimento ao turista falante de língua espanhola.

\section{LÍNGUAS PARA FINS ESPECÍfICOS}

A abordagem de Ensino-Aprendizagem de Línguas para Fins Específicos no Brasil surgiu na década de 70, voltada para o ensino de Francês, mas teve maior influência e consolidação a partir do Projeto Nacional de Ensino de Inglês Instrumental, criado pela Professora Doutora Antonieta Alba Celani durante a sua gestão na coordenação do programa de Linguística Aplicada e Ensino de Línguas (LAEL) da Pontifícia Universidade Católica de 
São Paulo (PUCSP) (RAMOS, 2005; ROSSINI; BELMONTE, 2015). Anterior a essa década, Ramos (2019, p. 24) explica que "o foco do ensino tinha como protagonista o professor, a língua era centrada no código e seu funcionamento fora do contexto". Isso significa, que não se ensinava com um propósito definido, portanto, as necessidades dos estudantes não eram levadas em consideração.

O projeto surgiu devido à procura de professores universitários de inglês que cursavam Pós-graduação em Linguística Aplicada ao Ensino de Línguas na PUCSP e não se sentiam preparados para oferecer cursos nessa área. Sendo assim, inicialmente foi voltado para a capacitação de professores de inglês das universidades brasileiras, logo estendeu-se às escolas técnicas federais (RAMOS, 2005; 2009; 2019; ROSSINI; BELMONTE, 2015).

Essa abordagem deu ao projeto uma característica "participativa", pois, segundo Celani, o desafio enfrentado por esse grupo foi o de romper alguns paradigmas acerca do ensino instrumental de línguas, porque, em geral, a preocupação era a de ensinar sintaxe e vocabulário. Essa equipe preocupou-se com as necessidades específicas de cada grupo, isto é, em definir os conteúdos, materiais e metodologias com base nas "razões para aprender e não em imposições decorrentes de políticas do momento ou de ditames da moda" (CELANI, 2009, p. 23).

Como a necessidade inicial foi a leitura de textos acadêmicos, a nomenclatura "Instrumental" ficou muito difundida apenas para leitura. Nas palavras de Oliveira e Silva Júnior (2019, p. 214), "En la literatura sobre la didáctica de las lenguas se género el mito de que la noción "instrumental" conlleva la idea de enseñanza solo de la lectura en dicho idioma."2 .No entanto, com os avanços tecnológicos e criação de novas áreas específicas no mundo laboral, os estudos desta abordagem exigiam o desenvolvimento também das outras habilidades das línguas como, por exemplo, desenvolvimento textual e compreensão oral, além da habilidade de leitura já existente, para melhor desempenho no mercado de trabalho.

Em 2012 a professora e doutora Rosinda Ramos adotou o termo Língua Para Fins Específicos (LinFe) em substituição ao Instrumental. Essa decisão se deve à compreensão da necessidade de dissociar a noção de que o ensino instrumental se resume ao ensino de leitura. A professora define LinFe como um curso baseado em necessidades dos alunos para contextos específicos, contendo linguagem, temas, conteúdos relacionados às áreas de atuação (Ramos,

\footnotetext{
${ }^{2} \mathrm{Na}$ literatura sobre a didática das línguas gerou-se o mito de que a noção "instrumental” implica a ideia de ensino somente da leitura em determinado idioma (Tradução Nossa).
} 
2019). Neste trabalho optamos por utilizar o termo Ensino de Línguas para Fins Específicos (ELFE), que também se associa a perspectiva de Ramos.

Atualmente, novas pesquisas com diferentes vieses têm se consolidado no Brasil, porém, a relevância desses trabalhos está na compreensão de que o ensino-aprendizagem de Línguas para Fins Específicos deve estar associado a outras abordagens metodológicas como, por exemplo, a etnográfica (ROSSINI; BELMONTE, 2015) e a intercultural (LIMA-DUARTE; GOMES, 2019).

Este breve panorama histórico do Ensino-Aprendizagem de Línguas para Fins Específicos demonstra a importância da apropriação das necessidades profissionais dos nossos alunos, de modo que se possa buscar diferentes perspectivas teóricas e metodológicas para contribuir com o ensino de línguas.

\subsection{ANÁLISE DAS NECESSIDADES}

A análise de necessidades pode ser considerada um instrumento que auxilia o ensino de línguas para fins específicos. Para Hutchinson e Waters (1987), ao se criar um programa de ensino de uma língua, primeiramente deve-se fazer a análise de necessidades.

Estes autores definem English for Specific Purposes (ESP) como uma abordagem que tem a motivação do aluno ao aprender o idioma como base para desenvolver os métodos e conteúdos nas aulas, ou seja, trata-se de "uma abordagem que se orienta pelo ensino baseado no aprendiz e nas suas necessidades" (VILAÇA, 2019, p.62).

As necessidades determinam, procuram e identificam as informações sobre o aprendiz e o que ele deve saber. Um professor que trabalha nesta perspectiva busca informações sobre meios de aprendizagem e sobre como a língua pode ou deve ser usada na situação-alvo. Sendo assim, primeiramente é preciso conhecer o contexto em que o aprendiz pretende atuar utilizando o idioma e depois conhecer a situação de aprendizagem.

Para tanto, Hutchinson e Waters (1987, p.53) partem da seguinte questão, "Diga-me o que você precisa no inglês e te direi o inglês que você precisa". Com base no nosso contexto de pesquisa, adaptamos essa frase para: Diga-nos quais são as suas vivências no ambiente de trabalho, como turista em Maceió e quais as suas necessidades no processo de ensinoaprendizagem de línguas para que possamos tentar adequá-las ao ensino de línguas no curso de Hotelaria no IFAL.

Hutchinson e Waters dividem a análise de necessidades em dois grupos: necessidadealvo, que corresponde a tudo o que é preciso aprender e saber em termos linguísticos para ser 
usado na situação-alvo e as necessidades de aprendizagem que tratam do que é preciso fazer (linguagem, habilidades e estratégias) para usar na situação-alvo. Nesta fase, consideram lacunas como o ponto inicial e as necessidades como o destino. (HUTCHINSON; WATERS, 1987, p.60)

Em termos gerais, as necessidades representam o que o aprendiz precisa saber, as lacunas diferenciam o que o aprendiz já sabe da língua e o que precisa saber e os desejos representam as diferenças daquilo que o aprendiz acha que precisa aprender e o que realmente ele precisa.

A análise de necessidades não pode ser simplesmente o início de um curso específico, mas sim um elemento da situação inicial, isto é, deve ser encarada como um processo contínuo, portanto, deve-se estar atento às críticas apontadas aos cursos em que se realiza esse estudo. $\mathrm{O}$ ensino de línguas em contexto profissional deve ter a visão detalhada dos participantes em relação ao ponto de partida e ao processo para que se possa encontrar soluções aos problemas no decorrer do curso.

\section{Procedimento metodológico}

Este estudo é de natureza qualitativa, pois de acordo com Denzin e Lincoln (2006), envolve uma abordagem interpretativa do mundo, por ser uma pesquisa sobre análise de necessidades, os pesquisadores investigam as coisas em seus contextos reais, tentando entendêlas de acordo com o significado que as pessoas lhes atribuem. Destaca-se que, embora a pesquisa seja qualitativa, os instrumentos de natureza quantitativa não são excluídos do processo, ao contrário, contribuem para a triangulação dos dados.

Para a realização da análise de necessidades é importante investigar diferentes fontes de informação (VIAN JR, 2002; RAMOS, 2019). Assim sendo, dividimos esta pesquisa em três processos de coleta de geração de dados, que ocorreram de modo concomitante, isto é, elaboramos e aplicamos um questionário semiestruturado nos hotéis, outro com os turistas e outro com os estudantes.

Nos hotéis, o questionário permitiu-nos verificar em contexto real as necessidades (HUTCHINSON; WATERS, 1987) nos usos das línguas espanhola e inglesa. Para tanto, o instrumento de coleta e geração de dados abordava sobre as experiências que os funcionários dos hotéis tiveram com os turistas estrangeiros e as possíveis dificuldades encontradas para realização dos atendimentos. Assim sendo, o questionário foi composto por perguntas como: Gostaria que você relatasse alguma experiência sua com hóspedes estrangeiros; Você já passou 
por alguma situação complicada por não compreender o que o hóspede estava solicitando? Caso você tenha passado por alguma situação de falta compreensão da língua, como você fez para resolver o problema? Quais as informações que os hóspedes estrangeiros mais perguntam no balcão?

O questionário aplicado aos turistas estrangeiros abordou questões relacionadas aos atendimentos prestados e aos serviços prestados ao turista. Este instrumento foi elaborado em espanhol e inglês com perguntas como: De onde você é? Você teve alguma experiência com a língua espanhola/inglesa que poderia nos dizer? (Algo que o recepcionista não compreendeu, alguma informação que no hotel, bares ou restaurantes não souberam dar?); Poderia nos dar alguma sugestão para resolução de problemas ou informações?

Enquanto aos questionários direcionados aos estudantes, também foram elaborados com base no modelo proposto por Hutchinson e Waters (1987) e buscaram compreender os desejos e as lacunas dos graduandos ao estudarem línguas estrangeiras. Como o questionário foi aplicado aos estudantes do primeiro ao quinto período, fizemos três adaptações. Um exemplo disso foi que no instrumento de pesquisa aplicado aos estudantes dos períodos iniciais focamos nas lacunas e nos desejos, já para os estudantes do quinto período nos preocupamos em saber se seus possíveis desejos e lacunas foram supridos durante o curso.

Para melhor compreensão acerca do processo de coleta e geração de dados, a seguir detalharemos por subseções cada etapa.

\subsection{Processo e COlETA E GERAÇÃo de dADOS NOS HOTÉIS}

No dia 10 de novembro de 2018 iniciamos o processo e coleta de dados junto aos hotéis de Maceió, o contato foi feito por e-mail, telefone e pessoalmente. Primeiramente entramos em contato com 15 hotéis. A escolha por esses hotéis foi baseada em suas localizações, uma vez que são situados nos principais bairros turísticos da cidade. Sendo assim, eram os hotéis que recebiam maior fluxo de turistas, inclusive, turistas estrangeiros que seriam fonte de informação dessa pesquisa.

Atendendo ao cronograma do nosso projeto de pesquisa, a coleta de dados ocorreu no início da alta temporada em Maceió (a alta temporada estende-se da segunda quinzena de novembro até o mês de janeiro), o que ocasionou a primeira dificuldade nesse processo, pois alguns hotéis estavam lotados e os responsáveis não puderam nos receber.

A segunda dificuldade foi o fato de que os possíveis colaboradores, supõe-se que por não terem vivenciado atividades de pesquisa durante sua vida acadêmica, não compreendiam a 
finalidade deste estudo. Ao percebermos essa problemática, elaboramos, em parceria com o Diretor de Pesquisa do IFAL, um documento explicando as etapas do nosso estudo e entregamos pessoalmente nos 15 hotéis. Destes, 10 dez deram um retorno e 06 seis aceitaram contribuir com o estudo. Ainda assim, mesmo com a declaração e o Termo de Livre Consentimento Esclarecido (TLCE) em que nos comprometemos a não identificar o hotel e os funcionários que contribuíram com o estudo, alguns responsáveis pelos hotéis declararam estar com receio de colaborar por medo de serem prejudicados. Após muito diálogo conseguimos dar continuidade ao processo de coleta e geração de dados.

Depois da autorização para a aplicabilidade dos instrumentos nos hotéis, iniciamos a observação de campo. Um dos pesquisadores realizou visitas in loco para identificar ocorrências e intercorrências nos atendimentos aos hóspedes estrangeiros. Esta fase contribuiu para a elaboração do questionário.

Como tivemos que esperar pela baixa temporada somente em fevereiro, aplicamos o questionário aos colaboradores. Nesta etapa contamos com a participação de 52 funcionários dos hotéis que desempenhavam as seguintes funções:

Figura 1 - Colaboradores hoteleiros por setor

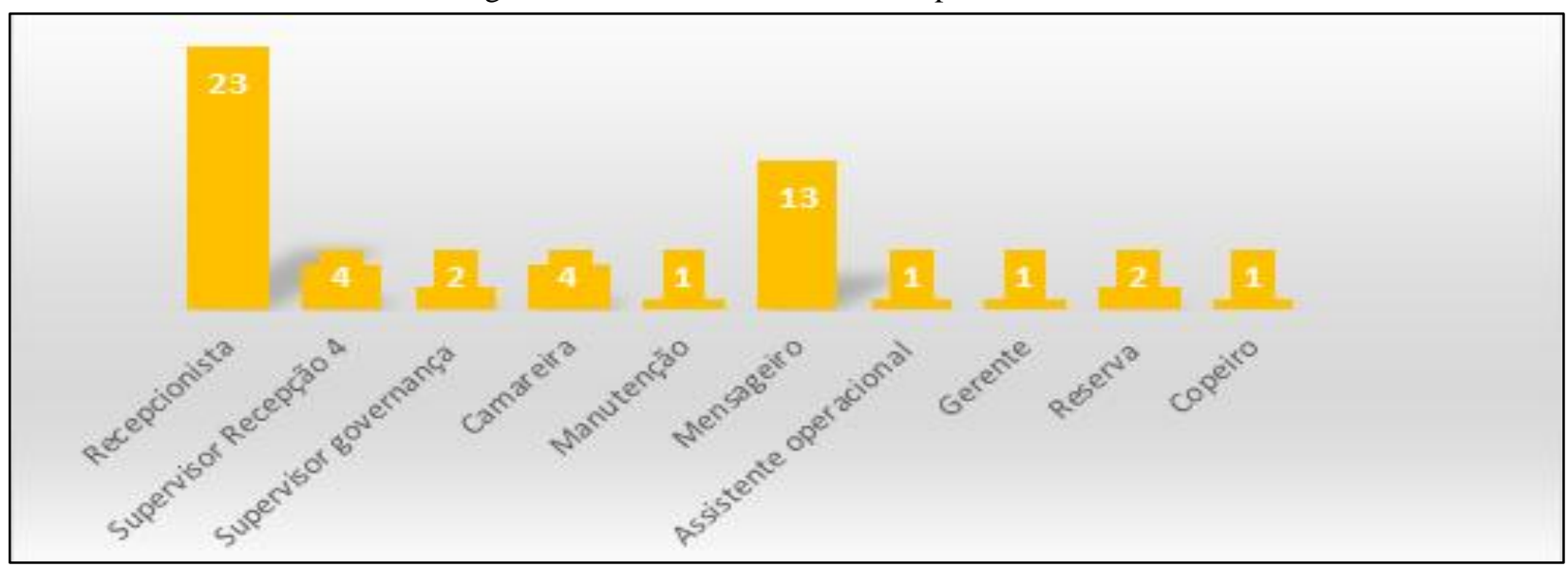

Fonte: Elaborado pelos pesquisadores.

Observa-se na Figura 1 que os funcionários que mais contribuíram com este estudo foram os recepcionistas e os mensageiros, dado que eles têm mais acesso aos turistas. No entanto, durante a fase de observação, notou-se que os demais funcionários também poderiam contribuir, pois cada função tem uma rotina ou necessidade específica e todas podem ajudar para que se tenha uma visão mais ampla das necessidades do futuro profissional de hotelaria. 


\subsection{ProceSSo DE COLETA E GERAÇÃo DE DADOS COM OS TURISTAS}

O processo de coleta e geração de dados com os turistas não estava previsto nesta pesquisa, no entanto, conforme foi relatado na subseção anterior (3.1), muitos hotéis se recusaram a colaborar com este estudo. Diante dessa dificuldade e das reflexões no grupo de pesquisa, consideramos importante ir falar diretamente com os turistas e os locais escolhidos para essa coleta foram: aeroporto e orla marítima de Maceió, locais estes que concentravam um grande número de turistas passantes.

Essa abordagem foi realizada por um dos bolsistas, visto que, ambos eram estagiários na Secretaria Municipal de Turismo-SEMTUR de Maceió $^{3}$, o que favoreceu o contato com o turista, pois ao fornecer informações sobre o estado, ele era convidado a participar da pesquisa. Apontamos que nesse processo nossa maior dificuldade foi a desconfiança de alguns turistas para assinar o TCLE. Contamos com colaboração de 10 turistas estrangeiros nativos de países que falam a língua espanhola. Não conseguimos contato com estrangeiros nativos da língua inglesa que aceitassem assinar o TCLE. Sendo assim, informalmente, falamos com duas pessoas nativas da língua inglesa ${ }^{4}$. A seguir elaboramos um gráfico detalhando as nacionalidades dos turistas colaboradores.

Figura 2 - Colaboradores hoteleiros por setor

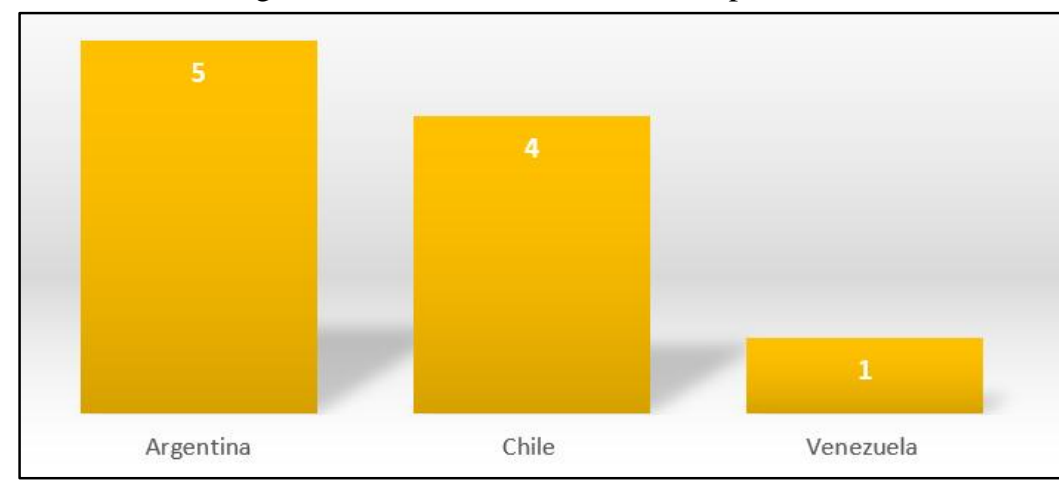

Fonte: Elaborado pelos pesquisadores.

Embora poucos turistas tenham respondido formalmente ao questionário (o que não prejudica na análise dos dados desta pesquisa qualitativa), nota-se que a maior participação foi dos argentinos, o que coaduna com os dados da Secretaria Estado do Desenvolvimento

\footnotetext{
${ }^{3}$ Destacamos aqui a contribuição da secretaria, na pessoa da coordenadora de informações turística, Maria Cristina Quirino, que permitiu a aplicação desta pesquisa.

${ }^{4}$ Os dados coletados nessa conversa não serão divulgados, visto que os turistas não se sentiram seguros para assinar o TCLE.
} 
Econômico e Turismo de Alagoas (SEDETUR), cujo estudo indica que 60\% dos visitantes estrangeiros em Maceió são oriundos da Argentina.

\subsection{PROCESSO DE GERAÇÃo DE DADOS COM OS ESTUDANTES}

Inicialmente o nosso projeto de pesquisa previa a coleta de dados com os professores graduados em Hotelaria que atuam no curso, contudo, após os estudos teóricos e a fase de coleta, percebemos que seria melhor ouvir os estudantes porque muitos deles já trabalham e interagem com os turistas e conhecem o uso dos idiomas no contexto profissional e mesmo os que não estivessem inseridos no mercado de trabalho dariam suas respostas baseadas em função de suas percepções.

Ademais, no que se refere à teoria da Análise das Necessidades, uma das categorias apontadas por Hutchinson e Waters trata-se do "desejo" dos estudantes, então, conhecer o que os estudantes desejam no curso e suas percepções de necessidades reais de uso das línguas em ambiente laboral são igualmente importantes para a análise. Por outro lado, para saber quais conteúdos são ministrados pelos professores da área técnica, bastava observar o Projeto Político Pedagógico do Curso.

Para iniciar a coleta de dados com os estudantes, foram elaborados 03 questionários e aplicados nas turmas de todos os períodos de hotelaria, que foram divididos da seguinte forma: questionário $n^{\circ} 1-1^{\circ}$ e $2^{\circ}$ períodos; questionário $n^{\circ} 2-3^{\circ}$ período; e questionário $n^{\circ} 3-4^{\circ}$ e $5^{\circ}$ períodos.

Figura 3 - Colaboradores estudantes

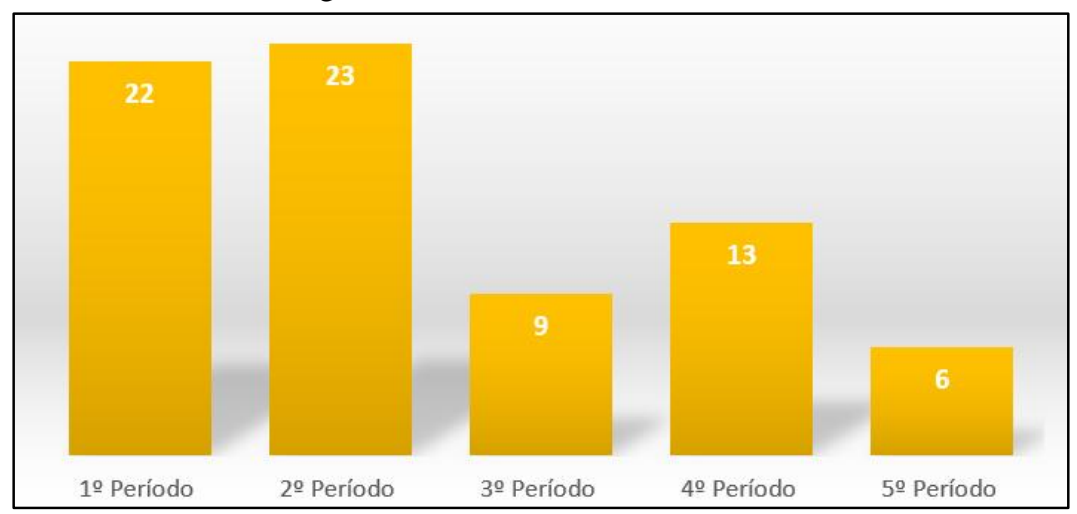

Fonte: Elaborado pelos pesquisadores.

Conforme pode ser observado na Figura 3, os estudantes do $1^{\circ}$ e $2^{\circ}$ períodos foram os que mais contribuíram com a pesquisa, isso se deve ao fato de que a partir do $3^{\circ}$ há mais evasão no curso. Além disso, no momento da coleta de dados, final do semestre letivo, os graduandos 
do $5^{\circ}$ estavam envolvidos em diversas atividades acadêmicas e preferiram não participar da pesquisa.

\section{ANÁlISE DE NECESSIDADES: AS PERSPECTIVAS DO PROFISSIONAL DA ÁREA, DO TURISTA E DO ESTUDANTE}

Nesta etapa, de análise dos dados, verificaremos as necessidades de usos das línguas espanhola e inglesa no curso Tecnológico em Hotelaria a partir das percepções de profissionais que atuam no ramo hoteleiro, turistas estrangeiros e estudantes, com base nas contribuições sobre a análise de necessidades de Hutchinson e Waters (1987). Nossa análise seguirá a mesma estrutura da metodologia e será subdivida de acordo com as categorias dos colaboradores participantes da pesquisa.

\subsection{FUNCIONÁRIOS DOS HOTÉIS}

As experiências vividas pelos profissionais que atuam nos hotéis e as situaçõesproblema contribuem na compreensão das necessidades e dificuldades enfrentadas no dia a dia. Portanto, uma das perguntas do questionário foi, "Poderia relatar alguma situação que você viveu ou presenciou por não compreender o que o hóspede estava solicitando?”. Devido a limitação de espaço no gênero acadêmico artigo, selecionamos dois relatos, um em inglês e outro em espanhol. Nosso processo de seleção foi com base em equívocos linguísticos que parecem simples, mas que podem acarretar certo desconforto tanto para o hóspede quanto para $\mathrm{o}$ atendente.

No início atendi uma família no resort onde trabalhava e eles queriam ir até a fazenda (Farm) e passei o endereço de uma farmácia (Pharmacy), mas um colega me ajudou e o erro foi desfeito. (RELATO DE A1, RECEPCIONISTA DO HOTEL H1).

No relato de A1, observa-se que ele utilizou o fenômeno de transferência da língua materna para a segunda língua, ou seja, A1 associou a palavra Farm a uma palavra semelhante ao de sua língua materna. O estudo de Análise Contrastiva fundamenta-se no conceito de interferência, isto é, na inclinação de o estudante a substituir traços fonológicos, morfológicos, sintáticos da LE por traços da LM (SELINKER,1972). Esta situação vivenciada por A1 não causou tanto problema aos hóspedes, pois seu colega conseguiu desfazer o equívoco. No entanto, este relato demonstra a necessidade de aprofundamento do estudo léxico relacionado a possíveis informações a serem solicitadas pelos hóspedes.

Na situação em espanhol, A2, fala sobre uma situação que envolveu o falso cognato 
pax $^{5}$ achou engraçado, mas não foi bom. (RELATO DE A2, RECEPCIONISTA DO HOTEL H2, 14/03/19).

Nesta situação descrita por A2 o hóspede não ficou chateado, porém, durante a entrevista, o colaborador da pesquisa disse que se sentiu mal com o ocorrido, o que o levou a estudar a língua espanhola. Os equívocos de A1 e A2 estão relacionados à transferência da língua materna para a língua estrangeira, o que reforça a necessidade de se ensinar mais os vocabulários relacionados à área de atuação desses profissionais. Para além disso, considera-se que essa experiência foi importante para que A2 refletisse acerca da necessidade de estudar a língua espanhola e de entender que o "portunhol" não é suficiente para o ambiente de trabalho.

Com o intuito de saber como eles resolvem os problemas de comunicação quando os conhecimentos linguísticos não são suficientes, perguntamos "Caso você tenha passado por alguma situação de falta de compreensão da língua, como você fez para resolver o problema?". Tendo, quantitativamente, o resultado de que a maioria deles resolve com o uso do Google tradutor, com mímicas e gestos.

Figura 4 - Formas de resolução dos problemas

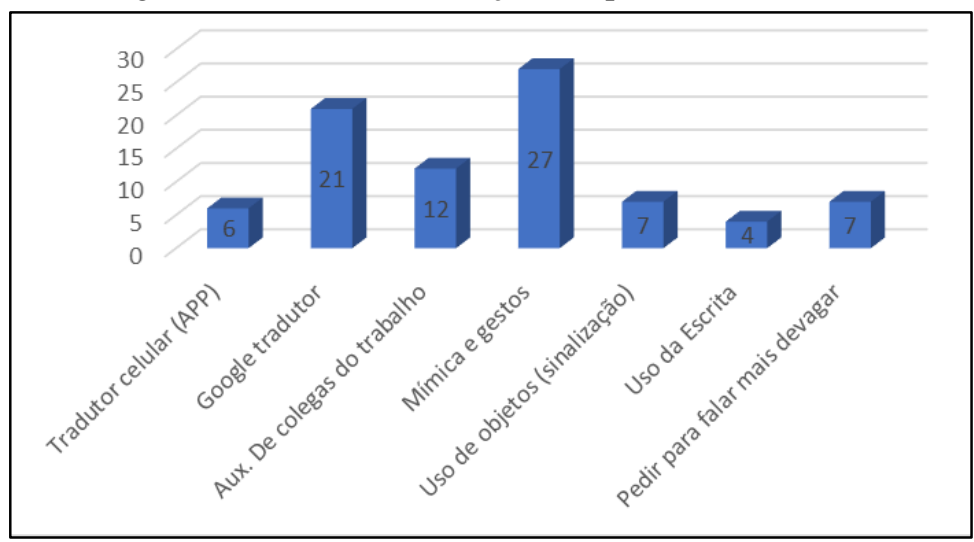

Fonte: Elaborado pelos pesquisadores

As mímicas e os gestos ficaram em primeiro lugar, posto que $90 \%$ dos colaboradores disseram usá-las quando não conseguem se comunicar verbalmente. Destaca-se que a linguagem multimodal (mímicas e gestos) é importante, no entanto, é necessário tomar cuidado porque alguns gestos utilizados no Brasil podem ser ofensivos em outros países e vice-versa. $\mathrm{O}$ uso do Google Tradutor ficou em segundo lugar com 70\%, porém, embora este aplicativo seja uma boa ferramenta, ele ainda apresenta muitas falhas de tradução, o que pode causar ruído na comunicação. $40 \%$ dos funcionários disseram contar com o auxílio de seus colegas de trabalho, esta postura é bastante interessante, porque além de solucionar a necessidade do hóspede e

\footnotetext{
${ }^{5}$ Termo utilizado por profissionais da área de turismo que significa hóspede.
} 
demonstrar que o hotel tem funcionários preparados para receber os visitantes de outros países, contribui com a relação interpessoal no trabalho. Houve um empate de $23,33 \%$ nas categorias "uso de objetos" e "pedir para falar mais devagar". A primeira estratégia assemelha-se ao uso de mímicas e gestos, e também pode se causar desgaste para o hóspede. A segunda, é uma boa estratégia, principalmente, em língua espanhola, pois como português e espanhol possuem a mesma raiz linguística, o funcionário poderá compreender o hóspede. $20 \%$ utiliza aplicativo de celular, o que assemelha ao uso do Google Tradutor. Por fim, 13,33\% dos hoteleiros informaram que tentam se comunicar pela escrita, este resultado, em conjunto com os demais demonstra que a lacuna está na interação verbal.

Para além desta análise quantitativa, vamos ilustrar uma situação de uso do Google tradutor em uma situação real, vivenciada por A3:

Em um check-in precisei virar a tela do computador para o hóspede e colocar no Google tradutor. Ele escrevia e virava para mim, eu lia e respondia" (RELATO DE A3, RECEPCIONISTA DO HOTEL H3).

Essa situação exposta por A3 e vivenciada por muitos outros, conforme análise da Figura4, demonstra o despreparo dos recepcionistas que atendem os turistas estrangeiros. Destaca-se ainda, que nem todo hóspede está disposto ou tem tempo para falar por meio dessa ferramenta, além disso, esse aplicativo pode proporcionar ao profissional uma falsa sensação de problema solucionado com relação a comunicação. Neste sentido, acerca das ferramentas tecnológicas utilizadas para a tradução, Abdalla afirma que elas

\footnotetext{
nem sempre oferecem ao usuário uma precisão, em função de que também este deve saber como aplicar as melhores estratégias de utilização e entender um pouco melhor as questões da língua, como seu contexto de uso, adequação lexical, conjugação verbal entre outros aspectos (2019, p. 118).
}

No ambiente de trabalho, onde a comunicação se dá de forma interativa e rápida, certamente, não será fácil para que o profissional da área de hotelaria faça as adequações linguísticas necessárias.

Dando continuidade à análise, perguntamos "Quais as informações mais solicitadas pelos hóspedes estrangeiros?". A partir da resposta dos colaboradores fizemos um gráfico para melhor ilustrar essas necessidades. 
Figura 5 - Informações mais solicitadas

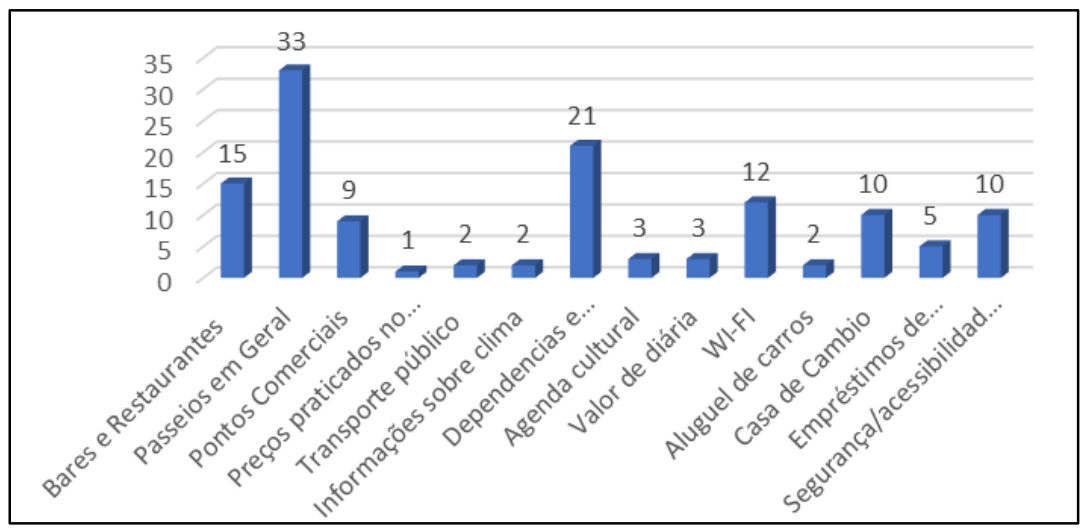

Fonte: Elaborado pelos pesquisadores

Como se pode verificar na Figura 5, as informações que os turistas buscam são referentes a: 94,28\% passeios em geral; $60 \%$ dependências e serviços do hotel; 42,85\% bares e restaurantes; $34,28 \%$ wi-fi; $28,57 \%$ segurança e acessibilidade na cidade; $28,57 \%$ casa de câmbio; $25,71 \%$ pontos comerciais (supermercados, shopping, farmácia); 14,28\% empréstimos de utensílios do hotel; 8,57\% agenda cultural, valor da diária; 5,71\% transporte público, informações sobre o clima, aluguel de carros; e 2,85\% preços praticados no comércio.

Estes resultados demonstram que a grande lacuna observada pelos hoteleiros a partir de sua atuação são atividades relacionadas aos serviços prestados. Sendo assim, torna-se necessário que as aulas de línguas estrangeiras espanhola e inglesa simulem os contextos de usos das línguas, praticando a realização de atendimentos em que o turista pede informações sobre as rotas turísticas do estado, dependências do hotel, dos lugares de diversão e do comércio existente no entorno no hotel. Segundo Silva Junior e Catellar (2019), nesse contexto o que mais importa é um conhecimento aprofundado de línguas que atendam as necessidades dos hotéis, funcionários e turistas. Vale salientar que para a realização desses diálogos simulando o contexto real, torna-se necessário aprender as estruturas sintáticas e semânticas básicas.

\subsection{TURISTAS}

Com o intuito de triangular os dados e ampliar a percepção no que se refere aplicamos a pesquisa com os turistas estrangeiros. Para saber as experiência e sugestões desses turistas relacionadas ao atendimento nos hotéis, fizemos a seguinte pergunta: Você teve alguma experiência com a língua espanhola/inglesa que poderia nos dizer? (Algo que o recepcionista não compreendeu, alguma informação que no hotel, bares ou restaurantes não souberam dar?). Selecionamos duas respostas, escolhidas a partir de experiências de falta de compreensão entre turista e recepcionista do hotel. T1 relatou sua experiencia sobre a comunicação via telefone: 
En el hotel es difícil la comunicación por teléfono, una vez necesitaba ir al aeropuerto, pregunté cuánto cuesta para aparcar, el chico me ha dicho que no había costo, pero hay" (RELATO DO TURISTA T1) ${ }^{6}$.

No relato de T1 observa-se uma dificuldade também relatada pelos funcionários dos hotéis, que se trata da comunicação por telefone. Observa-se que o funcionário tentou ajudar o hóspede, no entanto, a lacuna no que se refere ao vocabulário básico em língua espanhola prejudicou o entendimento.

Na segunda situação resolvemos destacar também um falso cognato de vocabulário

En desayuno yo pedí jalea de fresa y la chica sólo me hablaban "framboesa", decíame no tengo framboesa, pero después comprendí. Dificultad para elegir una comida, difícil comprender las palabras en portugués ${ }^{7}$. (RELATO DO TURISTA T2)

Neste relato mais uma vez podemos observar a necessidade de vocabulário para o preenchimento das lacunas. Além disso, pode-se verificar que os restaurantes dos hotéis, mesmo com o grande fluxo de turistas que falam espanhol, não se preocupam em colocar os cardápios em língua espanhola, o que dificulta ainda mais a comunicação entre os turistas.

Para não ficar apenas na análise das necessidades, com foco nas lacunas, fizemos uma pergunta aos turistas solicitando uma sugestão deles em relação ao que poderia ser melhorado: "Poderia nos dar alguma sugestão?” As respostas foram as seguintes: (1) Estudiar un poco más, las personas son amables, pero a veces es mejor hablar en portugués, algunas personas piensan que saben cómo hablar el español; (2) Unificar y ampliar la comunicación entre Brasil y Argentina; (3) Hablar despacio y conocer más palabras ${ }^{8}$.

Verifica-se que os turistas têm boa vontade em entender os brasileiros, mas apontam que é fundamental que eles ampliem o vocabulário, ou seja, é importante que os estudantes se detenham em ampliar o léxico da sua área de atuação. Este resultado coaduna com as lacunas verificadas nos hotéis e reforça a necessidade de que o processo de ensino-aprendizagem parta de contextos reais de uso da língua. Ademais, chamamos a atenção para vontade de o turista de que Brasil e Argentina ampliem a comunicação, o que nos remete à importância do ensino intercultural (LIMA-DUARTE; GOMES, 2009), dado que língua e cultura são indissociáveis.

\footnotetext{
${ }^{6}$ No hotel a comunicação por telefone é difícil, uma vez eu precisava ir ao aeroporto e perguntei se havia custo para estacionar, e o rapaz me disse que não havia custo, mais há. (Tradução nossa).

${ }^{7}$ No café da manhã eu pedi geleia de morando e a garota só dizia framboesa, dizia não tenho framboesa, mas depois compreendi. Dificuldade para escolher uma comida, difícil compreender as palavras em português. (Tradução nossa).

8 (1) Estudar um pouco mais, as pessoas são amáveis, mas às vezes é melhor falar em português, algumas pessoas pensam que sabem falar espanhol; (2) Unificar e ampliar a comunicação entre Brasil e Argentina; e (3) Falar devagar e conhecer mais palavras. (Tradução nossa).
} 
O conhecimento intercultural contribui não só para a aprendizagem da língua, mas para desconstruir estereótipos e aproximar os povos.

Como forma de sintetizar os resultados desta pesquisa aplicada aos funcionários dos hotéis e dos turistas com a finalidade de verificar as lacunas, elaboramos um quadro de análise das necessidades para área de hotelaria em Maceió.

Quadro 1 - Síntese de atividades a partir das percepções dos funcionários dos hotéis e dos turistas

\begin{tabular}{|c|c|c|}
\hline Recepcionista & Bares e Restaurantes & Secretaria de turismo \\
\hline $\begin{array}{l}\text { 1. Atender presencialmente e por } \\
\text { telefone } \\
\text { 2. Recepcionar o turista } \\
\text { 3. Dar informações sobre os } \\
\text { pontos comerciais e os serviços } \\
\text { ofertados } \\
\text { 4. Passar informações sobre os } \\
\text { pontos turísticos do estado } \\
\text { 5. Informar sobre os serviços e } \\
\text { dependências do hotel }\end{array}$ & $\begin{array}{l}\text { 1. Elaborar um cardápio em } \\
\text { português, espanhol e inglês } \\
\text { 2. Capacitar profissionais para } \\
\text { explicar os ingredientes dos pratos } \\
\text { em espanhol e inglês. }\end{array}$ & $\begin{array}{l}1 \text { - Sinalizar em espanhol as } \\
\text { estradas que levam aos pontos } \\
\text { turísticos próximos a Maceió. }\end{array}$ \\
\hline
\end{tabular}

Fonte: Elaborado pelos pesquisadores.

\subsection{ESTUDANTES}

Para finalizar a triangulação dos dados, fomos verificar com os estudantes as expectativas “desejos” em relação ao curso. Os resultados são apresentados graficamente pelas Figuras 6, 7, 8, 9 e 10.

Figura 6 - Expectativas dos Estudantes do $1^{\circ}$ Período, 22 participantes

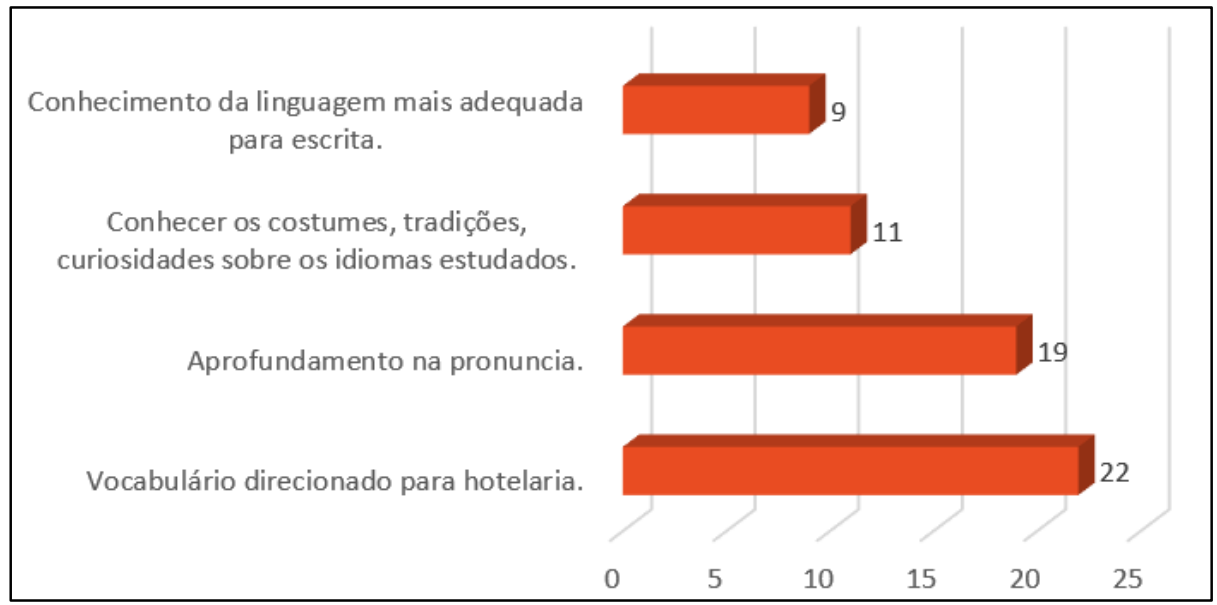

Fonte: Elaborado pelos pesquisadores. 
Figura 7 - Expectativas dos Estudantes do $2^{\circ}$ Período, 23 participantes

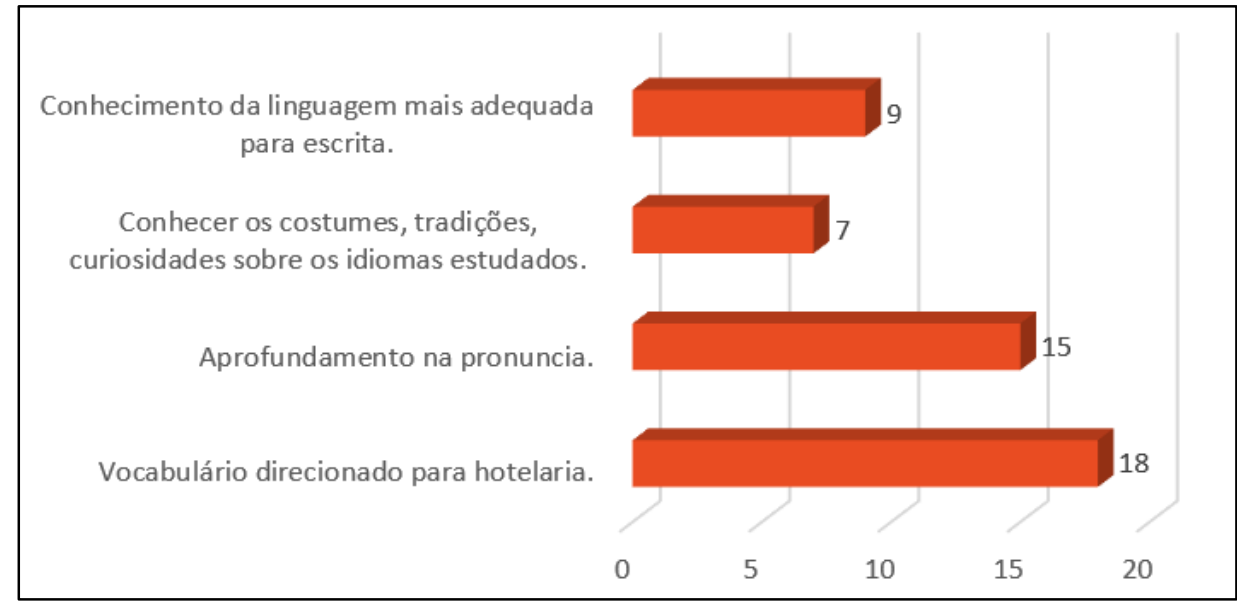

Fonte: Elaborado pelos autores

Figura 8 - Expectativas dos Estudantes do $3^{\circ}$ Período, 9 participantes

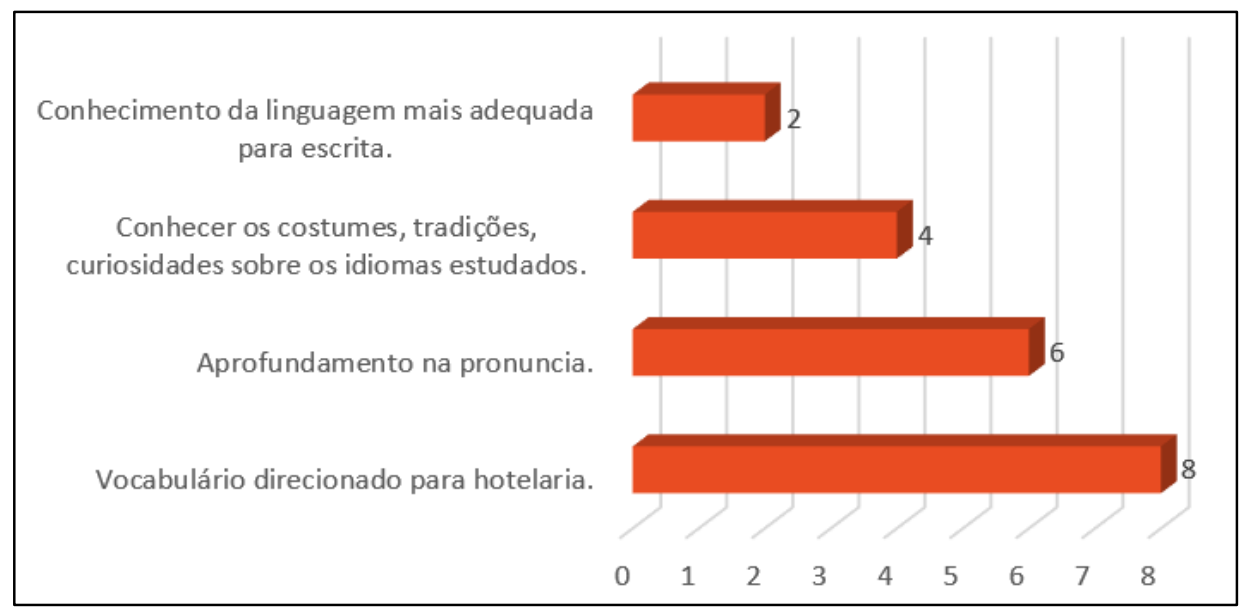

Fonte: Elaborado pelos autores

Figura 9 - Expectativas dos Estudantes do $4^{\text {o }}$ Período, 13 participantes

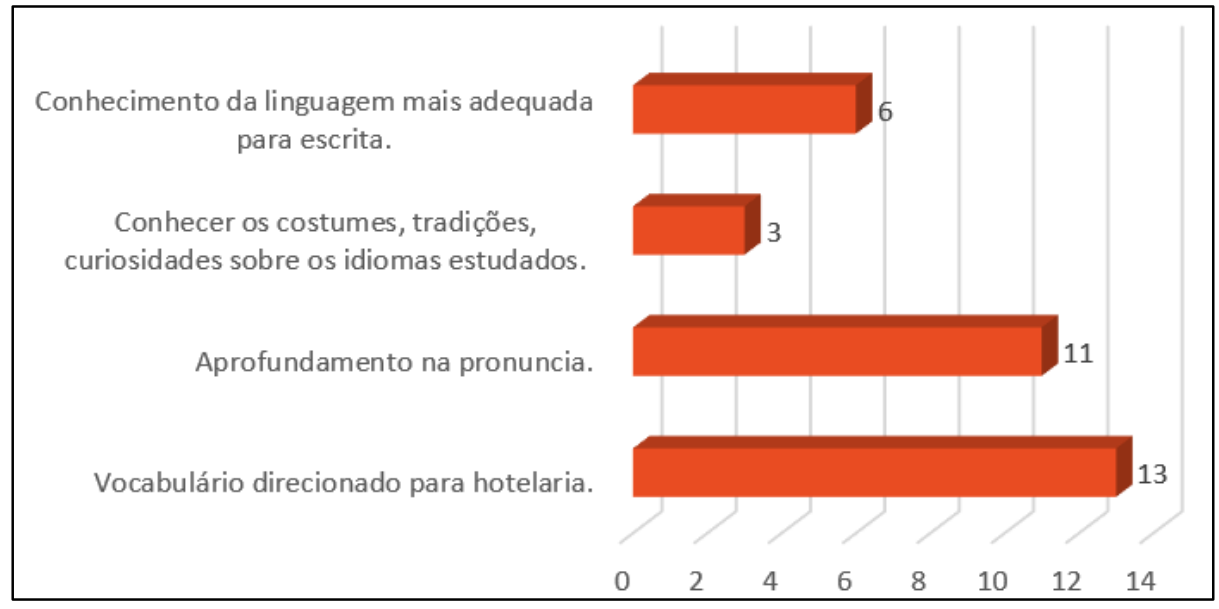

Fonte: Elaborado pelos autores 
Figura 10 - Expectativas dos Estudantes do $5^{\circ}$ Período, 6 participantes

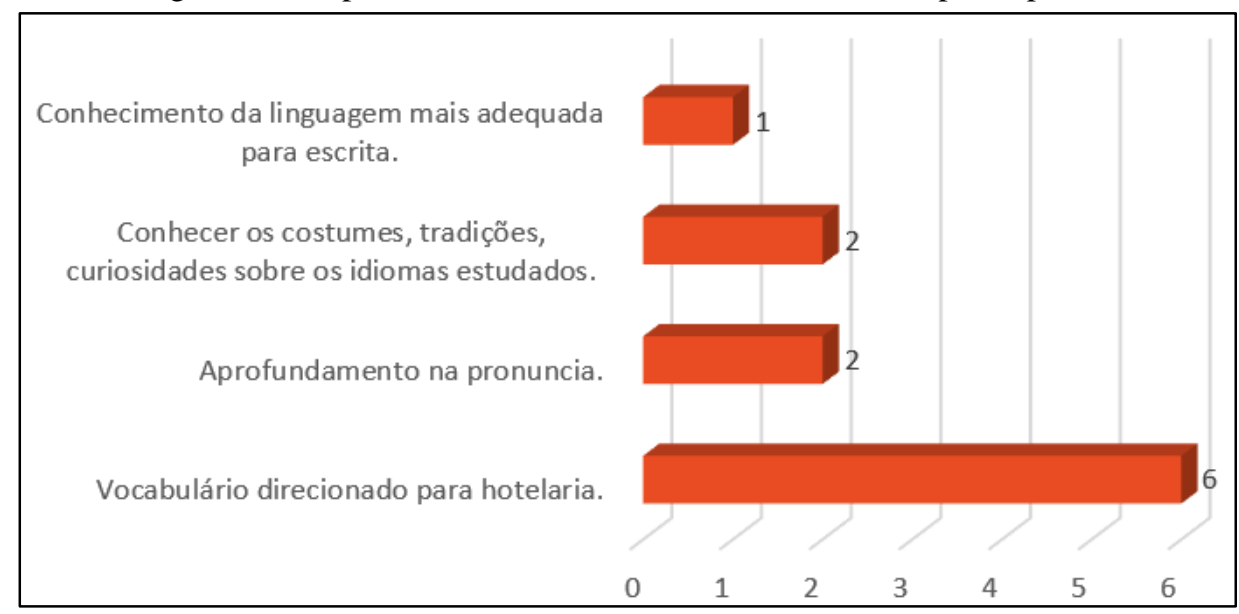

Fonte: Elaborado pelos autores

Conforme os dados da Figura 5, observa-se que a maioria dos participantes (64) disse compreender que "o mais importante no curso" é o ensino de vocabulário. Essa informação se relaciona com os resultados obtidos com os funcionários dos hotéis e com os turistas.

Para confrontar essa percepção, fizemos algumas perguntas abertas sobre a expectativa deles. Tendo em vista, que muitos estudantes participaram desta pesquisa, destacamos 5 expectativas apontadas por eles, uma expectativa por período entrevistado.

Espero que os professores foquem mais na conversação e na pronúncia. Gramática é importante, mas creio que na nossa profissão, a conversação é 90\%. Espero que mudem a metodologia de ensino (ESTUDANTE DO $1^{\circ}$ PERÍODO).

De acordo com o apontamento realizado pelo estudante do primeiro período, o curso deveria focar mais na conversação, contudo, ele certamente não observou as ementas das disciplinas, porque no primeiro período a ideia é que eles tenham uma base das línguas espanhola e inglesa para que depois entrem na parte específica. Além disso, destaca-se que as turmas possuem a média de 40 a 47 graduandos, o que certamente impossibilita que haja mais práticas de conversação nesse período.

Espero confiantemente em conhecer professores literalmente engajados, habilitados a realmente ensinar, serem mais objetivos tratar, mas assuntos vivenciados em hotéis, haja vista que, o curso não me proporcionará a língua totalmente fluente. Não há essa preparação aqui: e é isso. Esperar mais diálogos e assuntos voltados ao curso". (ESTUDANTE DO $2^{\circ}$ PERÍODO)

No segundo período, o estudante já começa a perceber a necessidade de que o ensino seja mais voltado para a área de hotelaria, no entanto, há um equívoco em sua parte ao pensar que precisa sair fluente do curso, dado que esta pesquisa está demonstrando que eles precisam de conhecimento básico. 
Para que possa ser um bom profissional é preciso melhorar o meu desempenho nas duas línguas (ESTUDANTE DO $3^{\circ}$ PERÍODO).

Neste depoimento, o aluno aponta a responsabilidade dele com relação a disciplina, o ensino é uma via dupla, isto é, o estudante é tão responsável pelo processo de ensinoaprendizagem quanto o professor (RAMOS, 2019). Este estudante apresenta uma visão mais madura em relação ao aluno do $2^{\circ}$ período, que coloca toda a carga no professor, como se ele não devesse se esforçar para aprender espanhol e inglês.

Esperava sair tendo a capacidade de me comunicar completamente nos idiomas, mas não ocorreu, embora sejam 2,5 anos (ESTUDANTE DO $4^{\circ}$ PERÍODO).

Diferentemente do estudante do $3^{\circ}$ período este estudante, não se coloca como agente no seu processo de ensino-aprendizagem. Ademais, ele, assim como o estudante do $2^{\circ}$ período, expressa uma falsa impressão de que o curso, de dois anos e meio e com apenas duas aulas semanais os tornaria fluentes nas duas línguas.

O ensino de espanhol me auxiliou no período do estágio. Mas o curso de inglês não me trouxe muito conhecimento, pois o que nos ensinaram era para decorar (ESTUDANTE DO $5^{\circ}$ PERÍODO).

Este estudante considera que o ensino de espanhol é mais contextualizado do que o inglês, e reconhece que o ensino daquela língua contribuiu para sua atuação profissional. É importante destacar que esta fala vai de encontro com a do estudante do $2^{\circ}$ período considera que o ensino seja descontextualizado.

Como pode- se observar, o desejo/expectativa da maioria dos estudantes é sair fluente do curso, contudo, esse desejo não condiz com a necessidade deles. O que comprova com o que Hutchinson e Waters (1987) dizem, que os desejos e as necessidades dos aprendizes podem ocorrer paralelamente e por isso nem sempre serão coincidentes, pois as necessidades podem ser definidas diante do contexto laboral, enquanto os desejos só são referentes aos aprendizes. Além disso, conforme observado na pesquisa com os funcionários dos hotéis e com os turistas estrangeiros, não há necessidade de ser fluente em espanhol e inglês, os conhecimentos de nível básico são suficientes para a interação entre o profissional e o visitante estrangeiro.

\section{CONSIDERAÇões FINAIS}

Objetivo inicial desta pesquisa era o de realizar um levantamento de necessidades dos usos das línguas espanhola e inglesa em hotéis em Maceió. Ao iniciar a pesquisa, percebemos que voltar o nosso olhar apenas para os hotéis não nos daria uma visão tão ampla do campo de atuação profissional da área hotelaria, portanto, decidimos complementar os dados com as contribuições de turistas estrangeiros e dos estudantes de hotelaria do IFAL, campus Maceió. 
Em relação aos funcionários dos hotéis e aos turistas, o resultado foi semelhante, isto é, os dois segmentos afirmaram que os estudantes precisam ampliar os seus conhecimentos léxicos. Outro resultado importante em relação aos turistas, trata-se da percepção deles de que os bares, restaurantes e o estado investem pouco para melhorar a comunicação em língua espanhola, pois, conforme indicado no decorrer deste artigo, a maioria dos turistas que contribuiu com esta pesquisa é nativo da língua espanhola. Esses turistas relataram os que nos hotéis, nos bares e nos restaurantes os cardápios e informações não são traduzidas para a língua deles, o que dificulta ainda na escolha dos produtos e a comunicação. Em relação ao estado, eles observaram que as sinalizações e as placas que indicam as cidades litorâneas próximas a Maceió não são traduzidas para a língua espanhola. Salientamos que esta é uma informação importante devido ao grande número de visitantes nativos da língua espanhola no estado de Alagoas.

Com base nos resultados dos atendentes da rede hoteleira e dos turistas há outro dado que merece ser destacado: a ausência de turistas que falam língua inglesa. Nesse sentido, embora a língua inglesa seja a principal língua falada mundialmente, no estado de Alagoas a língua espanhola é a predominante porque a maioria dos turistas que visitam alagoas, segundo a SEDETUR, são da América do Sul, o que corresponde a um total de $80 \%$ dos turistas estrangeiros. Sendo assim, podemos afirmar que o estado de Alagoas está na contramão aos excluir o ensino da língua espanhola das escolas estaduais, portanto, esta ação deveria ser repensada pelos governantes de Alagoas.

Em relação aos estudantes, os dados quantitativos apontaram que eles consideram importante estudar o vocabulário direcionado às áreas de hotelaria, mas ao questionarmos sobre seus desejos, muitos disseram que não saem fluentes do curso. Esse resultado demonstra que os estudantes possuem pouco conhecimento do que realmente necessitam em relação a essas línguas, visto que, conforme observado nos resultados coletados nos hotéis e com os turistas, a necessidade é que se tenha um nível básico dessas línguas e um conhecimento do léxico da área.

A partir da análise de dados da pesquisa realizada com os estudantes, percebemos que uma das lacunas deixadas neste estudo foi a de que não conversamos com os professores de línguas espanhola e inglesa que atuam no curso para que tivéssemos as suas percepções, o que certamente teria ajudado na triangulação dos dados. 
Por fim, consideramos que esta pesquisa contribuiu para que tenhamos uma visão mais ampla da área de hotelaria, de modo que consideramos que ela poderá ajudar na reformulação das ementas de língua espanhola e língua inglesa.

\section{REFERÊNCIAS}

ABDALLA, Glória Cortés. Ensino de espanhol para o curso de secretariado executivo: análise de necessidades e desafios atuais. In SILVA JÚNIOR, Antonio Ferreira Da: Línguas para fins específicos: revisitando conceitos e práticas. Pontes Editores, Campinas, 2019. p. 117- 131.

BERWICK, Richard. Needs assessment in language programming: from theory to practice. In: JOHNSON, Robert Keith (ed.). The second Languade Curriculum. Cabridge University Press, 1989. p. 48-62.

CELANI, Maria Antonieta Alba. Revivendo a aventura: desafios, encontros e desencontros. In: CELANI, Maria Antonieta Alba; FREIRE, Maximina. M.; RAMOS, Rosinda de Castro Guerra. A Abordagem instrumental no Brasil: um projeto, seus percursos e seus desdobramentos. São Paulo: EDUC, 2009. p. 17-31.

DENZIN, Norman K; LINCOLN, Yvonna S. O planejamento da pesquisa qualitativa: teorias e abordagens. $2^{\circ}$ ed. Porto Alegre: Artmed, 2006.

JOHNSON (ed.) The second language curriculum. Cambridge University Press.

HUTCHINSON, Tom.; WATERS Alan. English for Specific Purposes: a learning-centred approach. Cambridge: Cambridge University Press, 1987.

LIMA-DUARTE, Flávia Karolina; GOMES, Luiz Fernando. Interações multimodais em contexto intercultural: uso de tecnologia como recurso didático no processo de ensinoaprendizagem de língua espanhola para fins específicos. In. SILVA JÚNIOR, Antonio Ferreira Da. Línguas para fins específicos: revisando conceitos e práticas. Campinas, SP: Pontes Editores, 2019. p. 279-298.

RAMOS, Rosinda de Castro Guerra. Instrumental no Brasil: A desconstrução de mitos e a construção do futuro. In: FREIRE, Maximina. M, ABRAHÃ̃,Maria Helena Vieira. e BARCELOS, Ana Maria Ferreira. Linguística aplicada e contemporaneidade. São Paulo, SP: ALAB; Campinas: Pontes Editores, 2005.

RAMOS, Rosinda de Castro Guerra. A história instrumental na PUCSP. In. CELANI, Maria Antonieta Alba; RAMOS, Rosinda de Castro Guerra; FREIRE, Maximina M. A Abordagem Instrumental no Brasil: um projeto, seus percursos e seus desdobramentos. Campinas: Mercado das Letras; São Paulo: EDUC, 2009 Coleção- (As Faces da Linguística Aplicada) v. 10. 2009. p. 35- 45 .

RAMOS, Rosinda de Castro Guerra. De instrumental a LinFe: Percursos e equívocos da área no Brasil. In. SILVA JÚNIOR, Antonio Ferreira Da. Línguas para fins específicos: revisando conceitos e práticas. Campinas, SP: Pontes Editores, 2019. p. $23-41$. 
ROSSINI, Adriana Marroni Z.P; BELMONTE, Juliana. Panorama do ensino-aprendizagem de Línguas para Fins Específicos: Histórico, Mitos e Tendências. In. LIMA-LOPES, Rodrigo Esteves de. et al. Perspectivas em Línguas para Fins Específicos: Festschrift para Rosinda Ramos. Coleção: Novas Perspectivas em Linguística Aplicada, Vol 41. Campinas: Pontes Editores, 2015. p. 347-359.

SEDETUR (Secretaria de Estado do Desenvolvimento Econômico e Turismo). Secretaria de Estado do Desenvolvimento Econômico e Turismo (SEDETUR), 2020. Disponível em http://www.sedetur.al.gov.br. Acesso em: 07 set. 2020.

SELINKER; Larry. The Interlanguage. In: IRAL, International Review of Applied Linguistics in Language Teaching, 10(3). 1972. p. 209-232.

SILVA JÚNIOR, Antonio Ferreira Da; CASTELLAR, Thays Moreira. Línguas estrangeiras no trabalho de profissionais de turismo em Nova Iguaçu- RJ. In. SILVA JÚNIOR, Antonio Ferreira Da. Línguas para fins específicos: revisando conceitos e práticas. Campinas, SP: Pontes Editores, 2019. p. 189- 210.

VIAN JUNIOR, Orlando. Inglês Instrumental, inglês para negócios e inglês instrumental para negócios. D.E.L.T.A., Vol. 15, N Especial, 1999. p. 437-457.

VILAÇA, Márcio Luiz Corrêa. Para entender o ensino de inglês para fins específicos: Princípios, características e Ramos. In. SILVA JUNIOR, Antonio Ferreira Da. Línguas para fins específicos: revisando conceitos e práticas. Campinas, SP: Pontes Editores, 2019. p 5770 .

Recebido em: 28 de fevereiro de 2020.

Aprovado em: 30 de agosto de 2020. 